\title{
Modeling the coupling of ecology and biogeochemistry in the global ocean
}

\author{
STEPHANIE DUTKIEWICZ ${ }^{1}$, MICHAEL J. FOLLOWS ${ }^{1}$, \\ BEN A WARD ${ }^{2}$ AND FRANCOIS RIBALET ${ }^{3}$
}

\author{
${ }^{1}$ Massachusetts Institute of Technology \\ ${ }^{2}$ University of Southampton \\ ${ }^{3}$ University of Washington \\ Presenting Author: stephd@mit.edu
}

Phytoplankton are the base of the marine foodweb, drive biogeochemical cycles within the ocean, and impact the rates of air-sea exchange of carbon dioxide. These diverse microscopic organisms live in the sunlit portion of the water column, but are dependent on macro-nutrients such as nitrate and phosphate that are more plentiful deeper in the water column. We employ the concepts of resource competition theory along with a global scale numerical model to explore how the play off between the simultaneous needs for light and nutrients structures marine ecosystems and the biogeochemistry. The numerical model captures a diverse community of phytoplankton spanning different biogeochemical functional groups, several orders of magnitude in size classes, and a range of thermal requirements. The planktonic ecosystem is modelled within a dynamic physical and biogeochemical environment. We show that aspects of community structure, such as dominant species, size structuring, and trophic strategies, are largely controlled by the rate of supply of the limiting nutrients over vast tracts of the subtropical oceans. And in turn, by consuming the nutrients, the phytoplankton physiology sets the concentration of the ambient nutrients. We examine large gradients in environmental factors, such as temperature, and show how these impact growth and hence nutrient concentrations. We find that the anti-correlation between nutrients and temperature that is often observed, can actually be controlled by temperature-driven changes in plankton growth rates. We consider these finding within the context of observations from several cruises in the North Pacific Ocean.

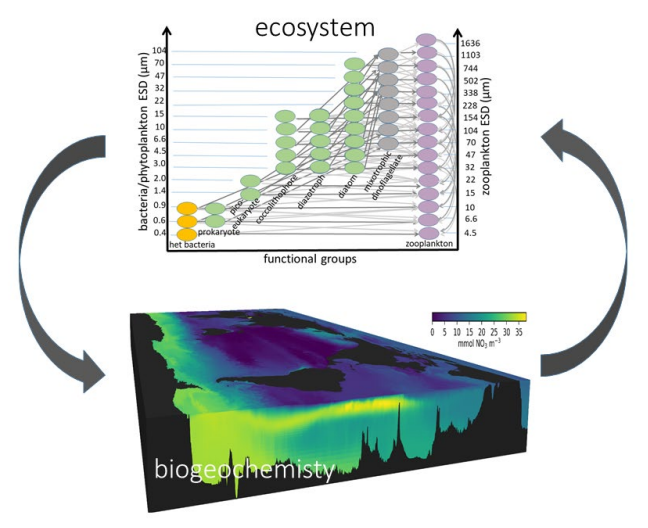

